\title{
PROTOINDUSTRIA E INDUSTRIA DISPERSA EN LA CATALUÑA DEL SIGLO XVIII. LA PAÑERIA DE ESPARREGUERA Y OLESA DE MONTSERRAT
}

\author{
ASSUMPTA MUSET I PONS \\ Centre d'Estudis d'Història Moderna \\ «Pierre Vilar»
}

\section{Introducción}

El objetivo de este artículo es el de analizar y exponer los rasgos básicos que caracterizaron la organización y evolución de la manufactura preindustrial de este núcleo del prelitoral catalán (Esparreguera y Olesa de Montserrat), dedicado a la elaboración de tejidos de lana.

Este análisis se ha hecho a partir de la aplicación de los principales puntos que configuran la teoría protoindustrial: tanto en el aspecto demográfico (crecimiento poblacional y vinculaciones con la expansión manufacturera); como agrario (capacidad productiva, distribución de la propiedad, etcétera); en la organización de la producción artesanal y gremial; en sus relaciones con el capital mercantil barcelonés; en su penetración por las redes comerciales supracomarcales (Cataluña y el mercado peninsular) y supranacionales (comercio colonial); como en sus aportaciones al proceso de industrialización catalán y en las causas que determinaron su desaparición a inicios del siglo xix.

La actividad manufacturera productora de bienes de consumo se caracterizó, ya desde la Edad Media, por su dispersión; primero por los núcleos urbanos y más tarde, a partir de la primera mitad del siglo xviI, por los rurales. Así, tanto los artesanos especializados como el campesinado, ocupado a tiempo parcial en la manufactura, realizaban el trabajo en su propio domicilio, independientemente y sin mantener ningún contacto con el resto de los productores encargados de los otros procesos técnicos, mientras que los comerciantes urbanos y los maestros fabricantes locales eran quienes ejercían el control y la coordinación de la cadena productiva.

A pesar de que durante el siglo xviII aparecieron ya las primeras manufacturas concentradas urbanas, el régimen de trabajo disperso se mantuvo en las operaciones de cardado e hilado hasta la implantación del sistema industrial. La historiografía tradicional ha sacado a la luz diferentes nombres para definir el grado de evolución y las características concretas de los diver- 
sos modelos de industria dispersa y, en especial, de la textil. Así, con el nombre de industria rural, se define aquella actividad artesanal más simple, ejerciaa pòr el campesino con un instrumental mù rudimentario y destinada a satisfacer sus propias necesidades de autoconsumo. La industria doméstica se corresponde ya con un estadio más evolucionado, en el cual las unidades familiares se dedican a la elaboración de artículos manufacturados destinados a un consumo más amplio y de carácter supralocal, implicando, por tanto, una mayor complejidad en la organización de la producción y en su comercialización; actividades que, en general, fueron asumidas por los maestros fabricantes locales.

Por su parte, ingleses y alemanes aportaron los términos de Putting-out system y Verlagsystem ${ }^{1}$ para definir la fase de máximo desarrollo de las manufacturas dispersas. Aquí se expone ya un sistema de producción mucho más complejo y con una clara dependencia del comerciante urbano o Verleger, encargado de coordinar, financiar y comercializar esta producción por los mercados suprarregionales y supranacionales.

Pero ninguna de estas definiciones reflejan con exactitud el verdadero espiritu de las manufacturas rurales dispersas, productoras de bienes de consumo y precursoras de lo que más tarde sería el modelo de producción capitalista. Es decir, en ningún caso se había intentado explicar la aparición del nuevo sistema productivo a partir de la existencia de una actividad industrial dispersa. Este será precisamente el vacío que intentará llenar la teoría protoindustrial ${ }^{2}$, dando así un nuevo enfoque a los estudios sobre industria dispersa y aportando, también, el aparato conceptual preciso para poder llevar a cabo este análisis. Análisis que exige un estudio global de todos y cada uno de los elementos de los que, necesariamente, se tenían que haber dotado estas actividades preindustriales para poder consolidar el nuevo modelo de producción.

En concreto, tenían que cumplir los siguientes requisitos: localización en áreas de agricultura subdesarrolladas y de bajos rendimientos, con una amplia participación del campesinado, que así conseguía unas rentas adicionales a los bajos sueldos agrarios. Comercialización a nivel suprarregional y supranacional. Predominio de la ciudad o núcleo urbano central, porque allí es donde residen los mercaderes que controlan esta producción y, también, porque allí se acostumbran a realizar las operaciones técnicas más complejas; mientras que al campo le corresponderían las más simples, pero que exigían mucha mano de obra (hilado). Predominio del capital variable (salarios) sobre el capital fijo (instalaciones) y existencia de unas áreas de agricultura comer-

\footnotetext{
' Véase A. González Enciso (1978), pp. 269-270, donde define las características de estos modelos de producción.

${ }^{2}$ F. Mendels (1972) y P. Kriedte, H. Medick y J. Schlumbohm (1986).
} 
cial vecinas de las manufactureras. Finalmente, la combinación y desarrollo de estos elementos permitiría a la manufactura preindustrial dotarse de todos

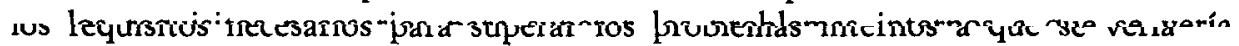
conducido el modelo disperso ante un incremento continuado del consumo; facilitándole su acceso a la plena industrialización a partir de la mecanización y concentración progresiva de la producción ${ }^{3}$.

En Cataluña existía una larga tradición de las manufacturas dispersas dedicadas a la producción de bienes de consumo, de entre los cuales había adquirido un notable desarrollo la industria pañera concentrada en unas áreas rurales muy concretas: Pirineo, Prepirineo y Prelitoral (comarca del Vallès y aledaños de Montserrat).

Sus características más destacables eran esta localización en zonas montañosas, de agricultura pobre y de escasos rendimientos, lo cual facilitó la penetración y expansión manufacturera; ocupando el tiempo vacante de este campesinado y proporcionándole un sueldo complementario. Una dependencia, sobre todo en el área prelitoral, del capital comercial barcelonés y la existencia de unas comarcas especializadas en una agricultura comercial. Por último, destaca el núcleo vallesano, formado por Sabadell y Terrassa, que consiguieron superar con éxito la etapa preindustrial y consolidar el proceso capitalista ${ }^{4}$.

Todos estos rasgos parecen encuadrarse perfectamente dentro del marco protoindustrial, pero la pañería catalana presenta también otras particularidades que no siempre son tan coincidentes con el paradigma propuesto por F. Mendels. Así, tanto J. Torras como J. Maluquer de Motes, están de acuerdo a la hora de reconocer que la especialización manufacturera de estas zonas catalanas se acentuó a partir del momento en que determinadas áreas del litoral se especializaron en el cultivo, producción y comercialización de vinos y aguardientes. La imposibilidad de elaborar los tejidos que necesitaban para su propio consumo les obligó a adquirirlos en estos núcleos con tradición artesanal, que así vieron incrementar sus demandas. Posteriormente, la expansión comercial del Principado, con los caldos y aguardientes como productos básicos, facilitaron también la penetración de estos artículos en los mercados peninsulares y coloniales 5 .

Nosotros, por nuestra parte, intentaremos llevar a cabo un análisis más concreto de la realidad de la industria dispersa catalana. Análisis que se hará a partir de la aplicación de los diferentes puntos que configuran la protoindustria (tanto a nivel demográfico, agrario, comercial y en sus relaciones

${ }^{3}$ Véanse R. Aracil (1983) y R. Aracil y M. García Bonafé (1980), donde exponen los principios de la protoindustrialización.

$4 \mathrm{~J}$. Torras (1984).

3 Véanse J. Maluquer de Motes (1984), p. 23, y J. Torras (1984), p. 126. 
con el capital mercantil) en una de las zonas pañeras más representativas de la Cataluña preindustrial (la montserratina) perfectamente ejemplificada en sus dos más activos y dinámicos centros: Esparreguera y Olesa de Montserrat $^{6}$. Nuestros objetivos primordiales serán, pues, por un lado, comprobar en qué aspectos se cumple la teoría y, por otro, descubrir cuáles fueron sus posibilidades para acceder a la fase fabril y, también, cuáles fueron sus aportaciones al proceso de implantación del capitalismo en el Principado.

\section{Crecimiento demográfico}

Una de las características más notables de la Cataluña del setecientos es, sin duda, el notable incremento poblacional. Incremento que también en nuestro caso es perfectamente corroborable a partir de la comparación de los censos de 1718 y $1787^{7}$.

El primero de ellos, y después de rectificar los valores originarios añadiendo un 20 por 100 cifra en que aproximadamente se ha calculado el error de dicho recuento ${ }^{8}$ - nos da unos valores que oscilan alrededor de los 1.361 habitantes para Esparreguera y 1.108 para Olesa; setenta años más tarde el Conde de Floridablanca contabilizaría un total de 2.705 y 2.454 habitantes, respectivamente. El incremento había sido del 1,004 en el primer caso, y del 1,15 , en el segundo.

Las fuentes de nutrición de nuestras poblaciones fueron básicamente dos. Por una parte, la propia aportación demográfica local, fruto del incremento de la natalidad y de una cierta reducción de la mortalidad y consecuencia de las mejoras alimenticias, sanitarias e higiénicas experimentadas en Cataluña durante esta centuria. Por otra, la inmigración procedente de su entorno rural, con una economía agraria poco desarrollada y con un crecimiento demográfico elevado, que se debía sentir atraída por la posibilidad de ocuparse en el sector pañero, constituye el segundo de los canales a partir de los cuales se alimentó este incremento humano. Incremento que tenía que aportar el potencial laboral necesario para asegurar la ampliación y expansión continuada de esta industria dispersa. La cual, ante la imposibilidad de acudir a la utilización de medios técnicos en las fases de elaboración del proceso productivo, tuvo que seguir recurriendo a una utilización cada vez mayor de la mano de obra agraria para hacer frente al incremento del consumo. Es decir, nuestra manufactura necesitaba disponer de una reserva laboral donde abastecerse de fuerza de trabajo y que le fue aportada por el crecimiento demográfico.

- Véase A. Muset i Pons (1987).

'P. Vilar (1966), V. 3, pp. 141.142.

C. Martinez Shaw (1985), p. 68. 
Algunos documentos de la época nos facilitan, en parte, el seguimiento de la evolución del sector artesanal y nos permiten, por tanto, corroborar si esta nueva población se ocupó en la manufactura. Efectivamente, disponemos de dos recuentos de las casas de maestros de Esparreguera ocupados en la pañería, el primero de ellos datado en 1732 y el segundo en $1747^{\circ}$. A pesar de las limitaciones que comportan (no incluyen a los oficiales ni a los aprendices, ni tampoco tiene en cuenta la ocupación del resto de los miembros de la unidad familiar, ni la participación del campesinado), reflejan perfectamente el incremento experimentado en estos quince años por el sector secundario, que vio aumentar sus efectivos humanos en un 42 por 100 , pasando de 148 a 218 maestros agremiados.

También en Olesa se hace patente la creciente ocupación manufacturera de la nueva población. Así, el censo de $1787^{10}$, que contiene un apartado donde se relaciona la población agrupada por oficios, nos permite hacer una valoración aproximada de este fenómeno, a pesar de la ambigüedad manifestada a la hora de agrupar los diferentes sectores manufactureros, los cuales fueron incluidos en el grupo de «fabricantes» y «artesanos», sin especificar el oficio concreto ni la rama artesanal. Pero, a pesar de todo, destaca por su notoria presencia la población dedicada al sector secundario, que, con 206 miembros, representa el 45,3 por 100 del colectiv̀o laboral. Es decir, casi la mitad de la población activa se dedicaba a la manufactura y hay que suponer que muy especialmente a la pañera.

En definitiva, pues, tanto en un caso como en el otro parece haber existido una clara vinculación entre el incremento demográfico y la expansión de la manufactura, cumpliendo así la primera de las exigencias de la protoindustria: disponer de una potente reserva humana que tenía que facilitar la mano de obra necesaria para asegurar la expansión de esta industria dispersa. Así, pues, tanto el crecimiento demográfico como el manufacturero fueron dos movimientos íntimamente relacionados y coincidentes en el tiempo.

\section{Sector agrario}

A pesar de que el crecimiento del sector agrario catalán a lo largo del setecientos fue un fenómeno bastante generalizado, que afectó a una buena parte de las comarcas del Principado y a partir del cual se sentaron las bases de su posterior crecimiento económico, también es cierto que hubo determinadas áreas que quedaron al margen de este proceso. Suelos pobres y terre-

' Arxiu de la Corona d'Aragó (ACA), Arxiu Notarial (AN), Esparreguera, Josep Noguera, L. 386, 1732, f. 36, e Ignasi Montoriol, L. 409, 1747, f. 42.

${ }^{10}$ J. Iglésias (1969), V. 1, p. 102. 
nos poco aptos para el cultivo dificultaron, en parte, este avance y sentenciaron la agricultura a una escasa rentabilidad, obligando a estas comunidades campesinas a buscar actividades laborales y económicas complementarias.

Esta parece haber sido la realidad del agro de estos dos núcleos del prelitoral catalán, según se desprende del análisis de dos libros cabreos correspondientes al siglo xviıI. El primero de ellos corresponde a Esparreguera para el período de 1703 a 1705 , mientras que el segundo recoge las confesiones de los enfiteutas olesanos entre 1735 y $1738^{\prime \prime}$. Su importancia radica en la abundante información que aporta sobre el sector primario de estas dos villas (tipos de cultivos, técnicas usadas, repartición de la propiedad, etcétera). Pero su utilización implica serias limitaciones, ya que no incluye ningún dato sobre las propiedades alodiales no sometidas al dominio del Monasterio de Montserrat, ni sobre la existencia de otros tipos de explotación de la tierra (rabassa morta, etc.). Pero, en definitiva, nos permiten trazar los rasgos básicos de esta agricultura.

Así, sus características más peculiares eran, concretamente en Esparreguera, el predominio de los cultivos de secano (olivo, vid y cereales) y de las técnicas extensivas, con una escasa incidencia del regadio y de los abonos de origen animal y una utilización masiva de la fuerza de trabajo humana. Olesa se diferenciaba por haber experimentado una cierta especialización en el sector oleícola ${ }^{12}$, una mayor presencia del regadío (cáñamo) y por la utilización de la mula como fuerza de trabajo. Pero, sin embargo, ninguno de estos fenómenos conoció un desarrollo total y, en general, sólo beneficiaron a un sector del campesinado, mientras que una buena parte de él quedó al margen de estos avances.

Otra característica era la desigual distribución de la tierra. Desigualdad que se hacía más patente en Esparreguera, donde el 65 por 100 del agro estaba en manos del 3,1 por 100 de los confesantes, mientras que el 35 por 100 de éstos no tuvieron acceso a ninguna pieza de cultivo; el resto de enfiteutas (61,7 por 100) controlaban tan sólo el 35 por 100 de las tierras de labor. También en este aspecto Olesa presentaba ciertas divergencias: aquí los desposeídos eran sólo el 11,3 por 100 de los registrados, pero predominaba, en cambio, una gran masa de pequeños propietarios (74,2 por 100 de los confesantes) que controlaban parcelas inferiores a los 10 jornales de trabajo de mula; el resto de las tierras se repartía entre un reducido número de grandes hacendados (0,9 por 100 de los enfiteutas) que controlaban el 22 por 100 del agro y un 13,52 por 100 de labradores que detentaban el resto de parcelas que oscilaban entre los 11 y los 80 jornales de arar de mula.

"ACA, AN, Esparreguera, Pau Castell, L. 362, 1703-1705, y Josep Noguera, L. 389, 1735.1738.

${ }_{12}$ P. Vilar (1966), V. 3, pp. $362-363$ y 416. 
Así, esta dedicación al sector oleícola no consiguió en Olesa fomentar un crecimiento económico generalizado a nivel agrícola: el predominio de la pequeña propiedad, un cierto avance de la viña (que arrebató terrenos al olivar), la escasa transformación técnica exigida por la elaboración del aceite y una comercialización reducida al mercado regional parecen ser, en parte, los causantes de este escaso desarrollo. Por último, era un cultivo que exigía muy poca dedicación por parte del labrador dejándole, por tanto, largas temporadas sin trabajo que muy bien podía dedicar a otras actividades. En definitiva, pues, en ninguno de los dos casos el sector agrario aparece capacitado para absorber el potencial laboral que el incremento demográfico aportaba, ni para asegurarles un crecimiento económico continuado. En estas condiciones, el trabajo manufacturero, que contaba con una larga tradición en esta zona, aparece como una actividad con muchas posibilidades de consolidarse entre esta población campesina. Actividad que, por un lado, tenía que ocuparles laboralmente durante las épocas que el campo les dejaba libres y, por otro, tenía que proporcionarles unos sueldos que complementasen los bajos rendimientos agrarios.

Como tendremos ocasión de corroborar a lo largo del presente artículo, éste fue un fenómeno que, efectivamente, conoció una notable expansión en Esparreguera motivado por el escaso desarrollo agrícola; pero, en cambio, no ocurrió en la misma proporción en Olesa, donde el parcial auge del sector oleícola, incapaz de generar por sí sólo un crecimiento económico sólido y permitiendo por tanto la presencia de una segunda actividad, sí que en cambio acaparó parte del potencial laboral local condicionando y frenando la expansión pañera. Es decir, Olesa, debido a un mayor desarrollo olivarero, conoció, en contrapartida, un menor crecimiento de la manufactura, que se expansionó sometida y condicionada por las posibilidades que el sector agrario le dejaba.

\section{Industria lanera, sistema gremial y capital comercial}

Para el estudio del apartado gremial, así como para definir el tipo de relaciones que a nivel productivo. financiero y comercial se mantuvieron con el capital metcantil urbano, disponemos de una documentación variada y, desgraciadamente, escasa. En concreto, tenemos a nuestra disposición diferentes ordenanzas laborales de los colectivos artesanales locales: en Esparreguera disponemos de las ordenanzas de los tejedores de 1627, de los pelaires de 1732 , de los retorcedores y tundidores de 1777 y las promulgadas por la 
Junta de Comercio en 1769, y en Olesa las otorgadas a los maestros fabricantes en $1751^{13}$.

Aparte tenemos la información extraída de las actas de Protocolos Notariales de Esparreguera, correspondientes al siglo xviII, y del llamado Libro de paraires, de Olesa ${ }^{14}$. En ambos casos los datos proporcionados permiten solamente dar una visión muy parcial de esta manufactura, ya que las reglamentaciones reflejan tan sólo el espíritu normativo que caracterizó al sistema gremial, pero nos esconden en cambio toda la actividad industrial y laboral realizada fuera del marco corporativo (trabajo de los fabricantes libres, del campesinado no agremiado, etc.). El segundo bloque documental presenta también serias limitaciones, ya que en este caso sólo se nos permite conocer aquellas actividades y contratos comerciales $e$ industriales de los cuales se tomaba acta notarial (adquisiciones de lana, etc.): el resto, pues, queda en la incógnita. Pero, a pesar de su parquedad, esta información constituye la base a partir de la cual hemos podido trazar algunos de los rasgos y aspectos evolutivos más característicos de esta manufactura dispersa.

Su proximidad a Barcelona y la abundancia de agua parecen haber favorecido, ya durante el medievo, el desarrollo de una industria pañera y la consolidación de una cierta infraestructura gremial, así como su participación en mercados supralocales. Es decir, se había superado aquel primitivo estado que antes hemos calificado de industria rural y se había consolidado ya aquella etapa posterior de la industria doméstica que J. Torras sitúa en la segunda fase de evolución de la manufactura lanera tradicional ${ }^{15}$, orientada seguramente a complementar la producción barcelonesa.

Este nuevo estadio no solamente implicaba un incremento de la producción, ante la ampliación del mercado sino también una mayor complejidad a la hora de organizar el proceso productivo y de gestionar la llegada de estos paños a los comerciantes urbanos para su venta. Debió ser ahora cuando contingentes notables de la originaria población campesina abandonaron su tradicional actividad agraria para convertirse en artesanos especializados en las diferentes fases productivas y dedicados por completo al sector manufacturero: tejedores, tundidores, retorcedores, pelaires y cardadores llenan las actas del Llibre de la cort d'Esparreguera del año $1593^{16}$.

Esta actividad debió contar, ya ahora, con la aportación a tiempo parcial

${ }^{13}$ Arxiu Històric Municipal d'Esparreguera (AHME), Documentació fotocopiada, Ordenacions de teixidors de 1627, de paraires de 1732 y 1769; Arxiu Històric Municipal de Barcelona (AHMB), Ordenanzas de Tundidores y Retorcedores de Esparreguera, Documentació Corporativa, 52, Reg. 1276, y Arxiu Històric Municipal d'Olesa (AHMO), Caja núm. 48, L. 1, doc. 44.

${ }^{14}$ ACA, AN, Esparreguera, Ls. 358 al 487, 1700-1799, y AHMO, Caja núm. 48, L. 1.

15 Véase J. Torras (1981), pp. 7 y ss.

16 AHME, Llibre de la cort d'Esparreguera, 1593. 
de la fuerza de trabajo campesina dedicada al cardado e hilado, que eran las operaciones que exigían más mano de obra y menos especialización técnica. Al frente de este aparato productivo rural se fueron consolidando los maestros fabricantes rurales, que se convritieron, así, en los dirigentes y organizadores de esta industria dispersa.

Pero parece que fue a partir de la primera mitad del siglo xvir (momento en que se hizo efectivo el traslado de la pañería urbana hacia su entorno agrario, a donde acudió en busca de mano de obra barata y abundante y de una menor presión gremial) cuando esta industria lanera local conoció una verdadera expansión y consolidación. El capital comercial pudo así aprovecharse de las perspectivas que esta área ofrecía y que debieron actuar de imán para atraer esta actividad urbana: unos colectivos artesanos dedicados totalmente al sector secundario, una potente reserva de mano de obra campesina excedentaria del agro y una infraestructura a nivel laboral y productivo en funcionameinto y bajo el control de los pelaires locales. El papel de estos fabricantes agremiados parece haber consistido en hacer de intermediarios entre los productores rurales (artesanos y campesinos) y los comerciantes urbanos, poniendo a su disposición el aparato productivo local. Es decir, la existencia de una infraestructura corporativa y el funcionamiento de un gremio de pelaires, menos desarrollado que sus homónimos urbanos, no impidieron ni frenaron la penetración del capital mercantil. Penetración que tuvo unas particularidades muy notables y que se hizo, al menos en parte, a través del aparato corporativo existente.

Esta expansión manufacturera provocó importantes reestructuraciones a nivel gremial, en un intento de fijar los derechos y obligaciones de los diversos grupos de artesanos delante de los maestros fabricantes, y que se reflejan en la otorgación de nuevas ordenanzas a los tejedores de Esparreguera (1627) y a los pelaires de Olesa (1620) y en la creación de nuevas organizaciones de artesanos como la fundación de la Devosió dels retorcedors de llana, de Esparreguera, en $1619^{17}$.

Durante el siglo xviII, y fomentado por la reactivación económica del Principado y por el incremento del consumo, tanto en los mercados internos como externos, la pañería siguió consolidando su presencia a nivel laboral y económico. Consolidación que una vez más tuvo su reflejo en la otorgación de nuevas leyes al gremio de fabricantes de Esparreguera, en 1732, y al de Olesa, en 1751, y que tenían que regir la fabricación de paños y las relaciones entre los pelaires y el resto de los sectores productivos ${ }^{18}$. Los rasgos más notables de esta industria dispersa seguirán siendo, a lo largo de esta

${ }^{17}$ AHME, DF, Ordenacions de teixidors de 1627, Devosió dels retorcedors de 1619, y AHMO, Caja núm. $48, \mathrm{~L} .1$, doc. 49.

is AHME, DF, Ordenacions de paraires de 1732, y AHMO, Caja núm. 48, L. 1, doc. 44. 
centuria, la existencia y funcionamiento de un variado abanico de maestros especializados en las diferentes fases técnicas del trabajo de la lana (pelaires, cardadores, tundidores, retorcedores y tejedores), que se agruparon en diversas organizaciones gremiales (en Esparreguera los pelaires lo hicieron bajo el patrocinio de Sant Miquel, los tejedores de Sant Sever y los retorcedores y tundidores de las Verges del Rosari y del Remei; mientras que en Olesa, tejedores y maestros fabricantes se unieron en una sola cofradía bajo la advocación, también aquí, de la Verge del Rosari). Todas ellas conocieroron en general, y especialmente la de los pelaires de Esparreguera, un funcionamiento bastante regular a lo largo de todo el siglo y dispusieron de sus propios órganos de gobierno y administración (consolat), ordenanzas, etc.

Estos artesanos, que ya no pueden considerarse como campesinos, seguirán trabajando bajo la dirección y coordinación de los pelaires locales. Paralelamente la pañería seguirá contando con la aportación del potencial laboral payés, tanto local como de su entorno rural, ocupado en las tradicionales tareas del cardado e hilado. Actividades que les proporcionaban un sobresueldo que les permitía mejorar su economía de base agraria y que es perfectamente demostrable a partir de los tornos de hilar que frecuentemente aparecen entre sus bienes ${ }^{19}$. También Francisco de Zamora y el censo de 1787 hacen mención de la ocupación manufacturera de estos sectores agrarios locales y comarcales ${ }^{20}$.

El colectivo de los maestros fabricantes se consolida a lo largo de la centuria como el grupo más sobresaliente de la vida pública local: tanto a nivel político, con una participación constante (sobre todo en Esparreguera) en el consejo municipal ${ }^{21}$; como social, con el derecho exclusivo de encabezar las procesiones religiosas ${ }^{22}$; y evidentemente gremial, con el privilegio de canar, visurar y marcar los paños con el sello del gremio ${ }^{23}$.

En Olesa este protagonismo se hallaba muy compartido con los sectores de los medianos propietarios, evidenciando, una vez más, el papel conseguido por los colectivos agrarios, consecuencia, evidentemente, del desarrollo oleícola.

Pero fue en el aspecto productivo donde estos hombres hicieron gala de su capacidad y poder, coordinando y gestionando todo el proceso manufacturero. Proceso que se iniciaba con la adquisición de la lana en los tradicionales mercados aragonés y extremeño, y que llegaba a sus manos a través de los comerciantes urbanos y locales. Ellos eran también quienes anticipaban

19 ACA, AN, Esparreguera, Ignaci Montoriol, L. 443, 1780, f. 42, y AHMO, Caja núm. 39, Inventario de Bonaventura Vila.

${ }_{20} \mathrm{~J}$. Iglésias (1969), V. 1, p. 241, y F. de Zamora (1973), p. 50.

21 AHME, DF, Compra de cargos municipales, 1741.

22 ACA, AN, Esparreguera, Josep Noguera, L. 372, 1712, f. 167.

23 AHME, DF, Ordenacions de paraires de 1732; AHMO, Caja núm. 48, L. 1, doc. 44. 
el dinero a los proveedores, recibiendo de nuestros pelaires una parte al contado y el resto pagadero en plazos de dos o tres años ${ }^{24}$. De esta manera, nuestros maestros fabricantes intentaban suplir la falta de capitales para la adquisición de las materias primas. El dinero era, pues, anticipado por el capital mercantil, que lo iría recuperando a medida que se fuera vendiendo la producción una vez tejida.

Esta capacidad de coordinación continuaba una vez la lana había llegado a nuestras villas mediante su distribución y circulación por los diferentes artesanos para su elaboración, y finalmente, después de realizados los últimos retoques, tramitaban su llegada a los mercaderes urbanos para que se encargaran de la comercialización de esta producción.

Parece ser que fue esta capacidad por organizar el ciclo de manufacturación lo que les aseguró el lugar más destacado (sobre todo en Esparreguera) en la escala social, política y económica local; mientras que el resto de artesanos y gremios quedaron sometidos a este dominio.

Respecto a las relaciones establecidas entre nuestros fabricantes agremiados y el capital mercantil barcelonés cabe destacar que, a pesar de la incapacidad local para financiarse la compra de la lana y gestionarse la comercialización de los paños, en cambio pudieron mantener su autonomía a lo largo de todo el proceso productivo haciendo trabajar a los sectores artesanales locales y vendiendo sus tejidos libremente a uno o más mercaderes. Es decir, existió una dependencia respecto a estos hombres. de negocios en aquellos sectores (financiero y comercial) que sobrepasaban sus posibilidades; pero en cambio consiguieron mantener su independencia formal a lo largo de la fase de elaboración.

Por otro lado, el capital mercantil practicó otros sistemas de penetración y de control de esta producción rural dispersa, haciendo trabajar directamente y $\sin$ la mediación ni protección de los pelaires a los llamados fabricantes libres. Es decir, aquellos grupos que actuaban al margen de los gremios locales y que debían ser, seguramente, maestros pobres y campesinos subocupados en la manufactura, que ante su incapacidad para comprar la lana, pagar los sueldos, etc., se veían obligados a depender de los comerciantes urbanos. Carrera Pujal cita uno de estos empresarios (Pau Miarons), mercader barcelonés que hacía trabajar a mans a estos sectores productivos más pobres ${ }^{25}$, que se veían así privados de la autonomía de sus homónimos agremiados y también de la posibilidad de disponer libremente de los tejidos que ellos fabricaban. En Olesa los fabricantes libres adquirieron una gran fuerza frente a los agremiados. Así, no solamente disponían de sus propias

\footnotetext{
24 AHME, DF, adquisición de lana (J. Burgues).

${ }^{25}$ J. Carrera Pujal (1945), V. 3, p. 103.
} 
instalaciones (enjabonadores, tintes, etc.), sino que trabajaban sin la supervisión técnica del consulado de pelaires. Finalmente, en la Concordia de 1751, fueron obligados a integrarse en el referido gremio y a cumplir sus leyes y ordenanzas. Yerō, a pesar de èsta derròta, consıguèroñ nacèr prevarecel-aalgunas de sus demandas: como la no obligatoriedad de usar las instalaciones del gremio, o ser eximidos del examen de maestría necesario para acceder a dicha corporación ${ }^{26}$.

En nuestro caso, pues, ni la existencia d ${ }_{\beta}$ una estructura gremial ni el predominio e independencia de los fabricantes locales, conceptos no previstos por la teoría protoindustrial, fueron motivos suficientes para frenar o impedir la penetración y dependencia respecto al capital mercantil. Dependencia que se materializó, por un lado, financiando y comercializando la producción de los sectores agremiados y, por el otro, haciendo trabajar directamente para ellos a los fabricantes libres.

Pero donde sí se mantuvo una total independencia y autonomía de nuestra pañería fue en los aspectos técnicos y humanos. Aquí no se produjo aquella división geográfica del trabajo manufacturero que asignaba a la ciudad —en nuestro caso Barcelona - la realización de los procesos técnicos más complejos y que exigían una mayor especialización e inversión en instrumental, mientras que al campo le correspondía la realización de las más simples (hilado), pero que precisaban mucha mano de obra. Nuestras manufacturas dispersas disponían de los artesanos especializados: tejedores, pelaires, etc.; de los útiles de trabajo: telares, tijeras de tundir, etc. ${ }^{27} \mathrm{y}$ de las instalaciones, tiradores, tintes, etc. ${ }^{28}$, suficientes y necesarios para llevar a cabo todo el proceso de transformación de la lana en la propia villa, sin tener que recurrir ni a las manufacturas ni a los artesanos urbanos.

Por otro lado, difícilmente Barcelona, donde la pañería estaba viviendo un vertiginoso retroceso desde inicios del siglo xvIr, hubiera podido asumir el papel que la protoindustria le asigna, y sobre todo en el momento en que se estaba gestando el nacimiento de la nueva industria algodonera, embrión de lo que más tarde sería el modelo de producción capitalista en Catalunya. Como conclusión, cabe resaltar que, efectivamente, existieron unos lazos muy fuertes $y$ unas relaciones muy diversas entre nuestra manufactura dispersa y el capital comercial barcelonés.

${ }^{26}$ AHMO, Caja núm. 48, L. 1, docs. 44 al 51.

${ }^{27} \mathrm{~F}$. Cros, tejedor de Esparregueta, poseĺa telares, pintas, etc. (ACA, AN, Esparreguera, Joan Ferrer, L. 463, 1776, f. 5).

${ }^{28}$ ACA, AN, Esparreguera, Ignasi Montoriol, L. 431, 1768, f. 431, y L. 443, 1780, fs. 211 y ss., y AHMO, Caja núm. 48 , L. 1 , docs. 4 y 44. 


\section{Comercialización y mercados de venta}

Una de las manifestaciones más notables del desarrollo económico catalán

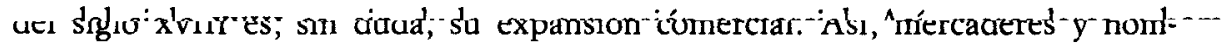
bres de negocios del Principado tuvieron en sus manos una buena parte del control de los intercambios, tanto en el ámbito peninsular como en el atlántico. Este comercio, basado principalmente en los vinos y aguardientes producidos en las comarcas del litoral, contó también con la presencia de otros artículos muy típicos de la industria y de la manufactura catalanas: así los paños de lana, sobre todo cuando se trataba de los prestigiosos tejidos de esta zona montserratina, tuvieron una presencia bastante continuada y un consumo asegurado, tanto entre la adinerada clientela barcelonesa y peninsular como entre la colonial.

En estas condiciones (expansión comercial y dominio del capital mercantil catalán) nuestra pañería parece haber gozado de una situación óptima para penetrar y consolidarse en los mercados supracomarcales y supranacionales, cumpliendo así otro de los preceptos protoindustriales: su introducción en las redes de distribución nacionales e internacionales. Hipótesis que intentaremos comprobar y confirmar a partir de la información extraída de diversos libros de contabilidad y de registro de entradas de mercancías de diferentes tenderos y comerciantes del Principado. A pesar de que esta información es, en general, escasa y reducida y que comprende un número muy limitado de firmas comerciales, es, también, la única fuente de que disponemos para realizar un análisis de este sector. Así, nos ha permitido conocer algunos de los mercados de consumo de esta pañería, el nombre de los fabricantes, el tipo de tejidos que se adquirían en esta zona, etc.

Pero, sin embargo, siguen existiendo muchas lagunas por cubrir, ya que en general se trata de series muy cortas, que cubren espacios muy limitados de tiempo y que, en el mejor de los casos, nos ha permitido tan sólo reconstruir el movimiento comercial a lo largo de trece años. En algunas ocasiones se omite la cantidad adquirida, así como su valor monetario, dificultando la cuantificación de estas ventas. Por último, esta información afecta solamente a una reducida parte de la producción local, impidiéndonos establecer las fluctuaciones, los volúmenes de comercialización, etc.

Disponemos también de otras noticias y referencias que documentan e ilustran su presencia en los mercados peninsulares y coloniales. Pero también ahora la escasez de datos impide hacer cualquier tipo de cálculo y solamente nos permite corroborar este destino a nivel suprarregional y supranacional.

En el marco regional catalán tenemos documentada la existencia de estos tejidos en diferentes botigues de Barcelona, y concretamente en los establecimientos de Duró y Llorens (quien, entre 1774 y 1783, hizo adquisiciones 
por un valor aproximado de 11.717 libras catalanas a Esparreguera, y de

2.153 a Olesa, que representaron el 12 y el 2 por 100 respecto al total de

paños comprados por la firma en Cataluña) v en la de Darrer v Duró. establecimiento seguramente filial del anterior, donde entre 1777 y 1780 se adquirieron un total de 53 y de 13 partidas, respectivamente; equivalentes al 12 y al 3 por 100 de las adquisiciones hechas dentro del Principado ${ }^{29}$. También P. Vilar ha detectado la presencia de artículos de Esparreguera en la botiga Amat, la cual, durante el período de 1764 a 1807, hizo un total de siete pedidos (10 por 100 de los tejidos de procedencia catalana) ${ }^{30}$.

También hemos podido testificar su presencia en algunas de las capitales de las dinámicas y activas comarcas agrarias de la Cataluña de la época, donde iban a proveerse de productos manufacturados los campesino de su entorno rural y donde vendían sus excedentes agrícolas (vinos, etc.). Así, nuestra pañería contó con una clientela segura en las comarcas vitícolas del Alt Camp. y concretamente en Valls, donde el tendero Joan Elias compró, entre 1754 y 1762, paños por valor de 4.760 libras catalanas (16 remesas) a diversos fabricantes de Esparreguera, y también en los establecimientos de Rafael Gallissà de Valls, en el de Pasqual Pasqual de Reus (Baix Camp) y en el de Pau Ràfols de Vilafranca (Alt Penedès). Cervera en la zona cerealista de la Segarra; Arbeca (les Garrigues) en pleno dominio del olivar; Mataró (el Maresme) en la activa franja costera; Berga y Santa Coloma de Queralt en el Berguedà; Manresa en el Bages; Tremp en el Pallars; Jussà y Sant Llorenç de la Muga en el Alt Empordà fueron asimismo clientes de esta pañería ${ }^{31}$. En concreto, Tremp y Sant Llorenç de la Muga (donde el comerciante Francesc Farigola adquirió, entre 1790 y 1802, dos partidas a Esparreguera y cinco a Olesa, que equivalen al 8,3 y al 7,2 por 100 , respectivamente, del total de sus compras) coinciden en ser dos zonas productoras de paños de lana, pero de menor calidad; así, este consumo se explicaría por tratarse de tejidos de mayor calificación que los locales (véase mapa 1).

Son en concreto los preciados paños y bayetas 22nos., 26nos., 30nos. y 32 nos., los que normalmente se adquirían en esta área de los contrafuertes montserratinos. Los nombres de los maestros fabricantes también suelen repetirse: son los Cabessa, Masdefiol, Reinés, Respall, Estruch o Montoriol en Esparreguera, y Bayona en Olesa. En definitiva, esta producción rural tuvo un consumo asegurado dentro del Principado, tanto entre la clientela barcelonesa como entre la comarcal.

${ }^{29}$ AHMB, Fons comercial, del A. 46 al A. 49, Darrer y Duró, 1777-1780, y B. 99 y B. 100 , Duró y Llorens, 1774-1783.

${ }^{30}$ P. Vilar (1968), V. 4, pp. $185-186$

31 AHMB, FC, B. 195, Francesc Farigola, 1790-1802; B. 88, Joan Elias, 1754-1762. ACA, AN, Esparreguera, Ignasi Montoriol, L. 410, 1748, f. 202; L. 401, 1748, f. 261; L. 416,1754 , f. 361 ; L. 437,1774 , f. 505 , y Pau Civil, L. 452,1757 , fs. 54 y ss. 


\section{MAPA 1}

Mexsolasucatelener

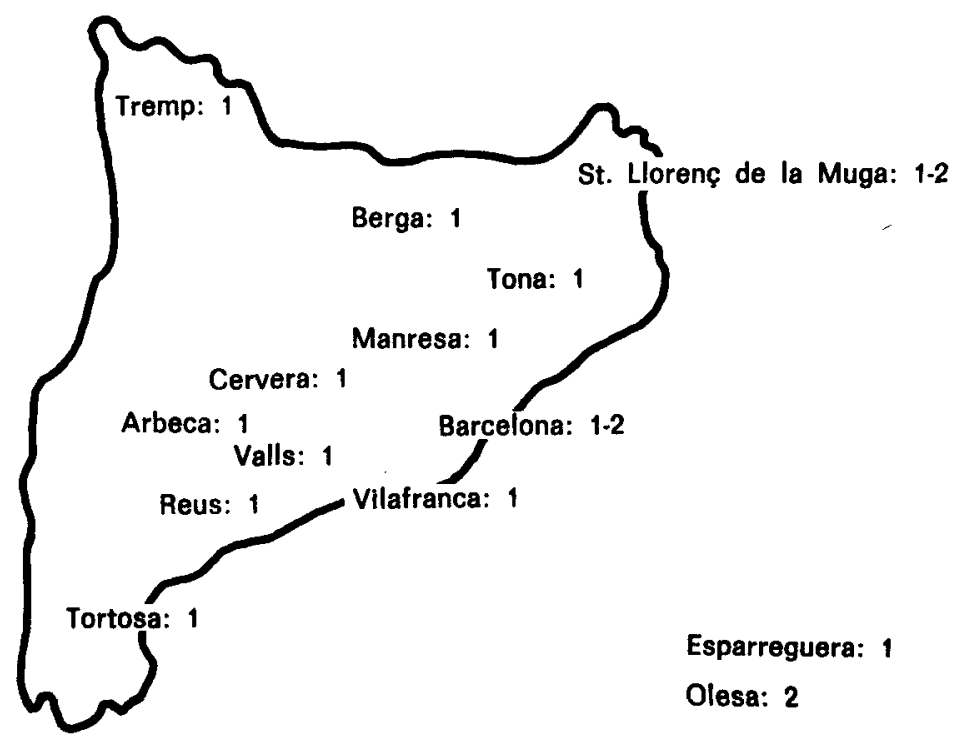

Fuentes: AHMB, FC, B. 195 , A. 88 , A. 46 al A. 49 , B. 99 y B. 100 , y ACA, AN, Ignasi Montoriol, L. 410,1748 , f. 202; L. 401,1743 , fs. 261 y ss.; L. 416, f. 361; L. 437, 1774, f. 505; Pau Civil, L. 452, fs. 54 y ss.

Para esta expansión interna nuestra pañería se benefió de los medios que el propio sistema comercial catalán había desarrollado, es decir, lo hizo valiéndose de la botiga y aprovechando las posibilidades que estos establecimientos ofrecían a la hora de distribuir y de hacer circular los productos de la manufactura catalana (en este caso de la montserratina) por los diferentes mercados comarcales; ya que tuvo en sus manos la distribución de una buena parte de la producción interna catalana. Este fenómeno nos corro. bora de nuevo los lazos y vinculaciones que existieron entre esta industria rural, en el aspecto comercial, y los hombres de negocios del Principado.

Por último, la penetración de estos artículos en la dinámica interna catalana a nivel comercial cumplió un objetivo básico y primordial: abastecer de productos manufacturados, en este caso tejidos de lana, a las comarcas 
especializadas en el sector agrario. Sector al que dedicaban toda su capacidad laboral, no pudiendo, por tanto, autoabastecerse de los productos industriales que necesitaban para su consumo y que podían adquirir en el mercado intercambiándolos por el dinero que la comercialización de sus excedentes agrarios les aportaba. La presencia de nuestros tejidos en algunas de estas comarcas demuestra claramente que, por su parte, cumplió el papel que la división geográfica del trabajo le asignó: la de cubrir las necesidades de consumo de las zonas agrarias. Pero esta circulación comercial interna tuvo su contrapartida con el abastecimiento de productos agrícolas hacia estas zonas especializadas en el sector manufacturero. Es decir, las comarcas agrarias proporcionaron a nuestros artesanos aquellos alimentos que su dedicación a la pañería les impedía autoproducirse, pero que también ellos podían comprar gracias a las rentas generadas por esta actividad secundaria.

Así parece corroborarlo la existencia de establecimientos públicos destinados a la venta de alimentos tan básicos de la dieta de la época como eran, por ejemplo, los cereales y de los cuales nuestras villas eran tradicionalmente deficitarias ${ }^{32}$.

En definitiva, pues, se establecieron, entre esta zona manufacturera y las agrarias, unas relaciones comerciales recíprocas y, por tanto, una dependencia mutua a la hora de abastecerse de aquellos géneros no producidos a nivel local.

En definitiva, pues, se establecieron, entre esta zona manufacturera y tras manufacturas en algunos mercados peninsulares: concretamente en Aragón, donde enviaban sus paños los fabricantes Pasqual Pasqual, de Esparreguera, y Salvador Gotzems, de Olesa ${ }^{33}$.

Otro sector hacia donde se canalizó parte de esta producción fue el suministro de paños para los uniformes del ejército. Suministro que tenian asegurado tanto por la calidad de los tejidos como por el control que los mercaderes barceloneses ejercían sobre los arrendamientos de este abastecimiento ${ }^{34}$.

Estas adquisiciones debieron ser, en determinados momentos, muy importantes, ya que movilizaron notables cantidades de lana, dinero y mano de obra. En Esparreguera se crearon diversas compañías de maestros fabricantes, los cuales unían así sus instrumentos, sus conocimientos y su capacidad de producción para dar más agilidad a estas demandas de la Corona ${ }^{35}$.

${ }^{32} \mathrm{El}$ año 1800 , el Ayuntamiento de Olesa se lamentaba que el cereal que se recogía en la villa era insuficiente para la manutención de los vecinos que lo cultivaban (AHMO, Caja núm. 48, L. 1, doc. 29).

${ }_{33}$ ACA, AN, Esparreguera, Ignasi Montoriol, L. 402, 1740, f. 118, y AHMO, Caja núm. $48, \mathrm{~L}$. 1 , doc. 63.

${ }^{34}$ Véase, para los asientos militares, P. Molas (1971), pp. 94 y ss.

${ }^{33}$ Josep Reinés, Brígida Ramon y Pere Casanovas formaron una compañía dedicada a 
En Olesa, a finales del siglo xvirr (1795), se llegó incluso a edificar unos nuevos tiradores para dar más pronta salida a esta producción ${ }^{36}$.

Disponemos, por último, de diversos testimonios que documentan el destino atlántico de una parte de esta pañería. Tanto P. Vilar como Carrera Pujal han detectado la presencia de los tejidos de esta zona entre los productos comercializados por la casa Alegre y por Pau Miarons, en el Nuevo Mundo ${ }^{37}$.

Este destino suprarregional, que parece tener garantizado tanto por la expansión comercial catalana como por las vinculaciones que existieron con los hombres de negocios del Principado, debió de tener importantes consecuencias para nuestra pañería: así, por una parte, implicaba una producción en masa destinada a abastecer estos amplios mercados externos con una notable participación de la población laboral local (campesina y artesana) y, por la otra, el establecimiento de unos estrechos lazos entre esta manufactura y las fluctuaciones de unos mercados muy lejanos $\mathrm{y}$ en pleno crecimiento ${ }^{38}$.

En definitiva, pues, en el plano comercial esta manufactura se adapta perfectamente a los principios teóricos de la protoindustria, tanto a nivel interno como externo.

\section{Industria dispersa e industrializacion}

Nuestras industrias dispersas podían proporcionar al sistema de producción capitalista toda una serie de elementos que, según el paradigma de F. Mendels, eran necesarios para poder poner en marcha el nuevo modelo de producción. Así, por una parte, podían aportar las bases humanas, es decir, la mano de obra proletaria y los sectores empresariales, que se podían abastecer de los colectivos de artesanos y pelaires locales; los capitales, acumulados a partir de la comercialización de esta producción dispersa y que eran necesarios para financiar las innovaciones técnicas y de instalaciones que se requerían; podía proporcionar también la capacidad y la experiencia de los maestros fabricantes locales en organizar y coordinar el proceso de producción y, finalmente, su penetración y participación en unas redes comerciales ya consolidadas, tanto a nivel interno como externo, y donde ahora se podrían

la fabricación de paños para el ejército (ACA, AN, Esparreguera, Pau Civil, L. 460, 1769, f. 313).

36 AHMO, Caja núm. 48, L. 1, docs. 23 y 23 bis.

${ }_{37}$ J. Carrera Pujal (1945), V. 3, p. 103, y P. Vilar (1968), V. 4, p. 514.

${ }^{38}$ En 1797, un pelaire de Esparreguera se lamentaba de las graves consecuencias ocasionadas a la industria local por la guerra anglo-española ( $A C A, A N$, Esparreguera, Joan Ferrer, L. 486, 1797, f. 243). 
vender los artículos de la nueva industria y donde también se podría abastecer de alimentos el nuevo proletariado.

La disponibilidad de todos estos elementos tenía que permitir a nuestra manufactura dispersa superar los graves problemas internos a que inevitablemente se vería conducida ante el incremento continuado de la demanda y la ampliación de los mercados; ya que el mantenimiento del tradicional sistema extensivo comportaba un incremento de los costes de producción y un alargamiento excesivo de la fase productiva que hacía poco competitivos estos artículos en los mercados. Así, la superación de las limitaciones impuestas por la manufactura preindustrial pasaba, necesariamente, por la concentración y mecanización progresiva del proceso productivo.

También la existencia de abundantes recursos hidráulicos (proporcionados por el río Llobregat), de una buena vía de comunicación (el camino real que procedente de Barcelona pasaba por Esparreguera) y su proximidad a la ciudad condal (primer centro industrial y comercial del Principado) eran factores positivos para el desarrollo fabril. Incluso se habían iniciado, ya durante la fase preindustrial, algunos tímidos avances que se materializaron en la formación de pequeñas compañías (en Esparreguera) que permitieron una cierta concentración de la producción, realizando en un mismo lugar varias operaciones técnicas. También la existencia de los llamados fabricantes libres, perfectamente diferenciados de sus homónimos agremiados, eran ya un primer paso hacia una liberalización progresiva de la producción.

Sin embargo, y a pesar de que aparentemente se daban unas condiciones favorables, ya que se podían aportar todos los elementos exigidos por la protoindustria, nuestras manufacturas laneras dispersas se vieron afectadas por un proceso irreversible de decadencia. Decadencia de la que jamás volverían a recuperarse y que provocó la ruina y la desindustrialización de esta zona.

Diversas son las causas que parecen explicar este fracaso y que se manifestaron, principalmente, en la incapacidad de los sectores dirigentes para dotarla de los medios técnicos y de las instalaciones necesarias para consolidar el cambio de modelo productivo. Es decir, en nuestro caso no se produjo aquella necesaria sustitución de la mano de obra por la máquina, sino que permaneció en vigor el modelo extensivo heredado de la edad media. En este proceso de estancamiento $e$ involución parecen haber influido fenómenos diversos: por una parte el gremio de pelaires, temeroso de que cualquier actividad realizada a sus espaldas implicara una pérdida de su poder, optó por obstaculizar y abortar todo intento de trabajo extragremial, impidiendo la actividad de los fabricantes libres y la elaboración de tejidos no previstos por las ordenanzas ${ }^{39}$.

${ }^{39}$ AHME, DF, Pleyto del gremio de pelaires... contra Josep Estruch, 1790; AHMO, Caja núm. 48, L. 1 , docs. 54 y 57. 
Por otro lado, el vaciado de dos libros cabreos correspondientes a Esparreguera (1759-1768) y a Olesa $(1735-1738)^{40}$, sitúa al grupo de los maestros fabricantes entre los principales propietarios de bienes inmuebles a nivel local. Predominio que se hace más patente en Esparreguera, donde constituían el 36 por 100 de los confesantes y controlaban alrededor del 40 por 100 de las tierras y el 26 por 100 de las casas registradas. En Olesa este predominio no era tan espectacular: aquí solamente representaban el 6 por 100 de los propietarios y tuvieron en sus manos, aproximadamente, el 4 por 100 de las parcelas valoradas en jornales de cavar y de arar de mula, el 8 por 100 de las labradas con buey y el 6 por 100 de las viviendas.

Esta tendencia a invertir en bienes inmuebles implicaba una desviación de los capitales aportados por la comercialización pañera hacia los sectores rentistas y, evidentemente, una descapitalización a nivel industrial que en nada tenía que favorecer la financiación de las innovaciones exigidas por la industrialización. Esta costumbre de adquirir tierras permaneció inalterable por razones diversas: por una parte, porque reforzaba aún más su prestigiosa condición de maestros fabricantes y les proporcionaba unas rentas sustanciosas y, por la otra, porque era una inversión que no estaba expuesta a los riesgos de las experimentaciones industriales.

Pero la actividad de nuestros pelaires deja una pregunta en el aire: ¿por qué se destinaron estos capitales a la adquisición de tierras y no a la modernización de la industria lanera como estaba ocurriendo en Sabadell y Terrassa? La respuesta parece obvia: seguramente porque no se vieron obligados a escoger esta segunda opción, es decir, no debieron tener la necesidad de sustituir la mano de obra por capital y, en consecuencia, por máquinas, para hacer frente a los incrementos de la demanda, sino que nuestros fabricantes debieron seguir recurriendo a la tradicional flexibilidad y baratura de la abundante mano de obra de su entorno rural, siempre dispuesta a ganar un sueldo complementario. El hecho de disponer de esta notable reserva humana les debió permitir afrontar los incrementos del consumo sin tener que aportar capital ni introducir innovaciones tecnológicas.

Evidentemente, el mantenimiento de este modelo productivo arcaico y tradicional, incapaz de competir con las nuevas industrias de Sabadell y Terrassa, debió provocar un grave retraso en el proceso de evolución capitalista, un encarecimiento de los artículos y la consecuente pérdida de sus tradicionales mercados ante el avance de la producción fabril, que podía sacar sus artículos en mayor cantidad, rapidez y bajo precio. Se consolidaron, por tanto, unas diferencias y unos atrasos muy difíciles de superar.

${ }^{40}$ ACA, AN, Esparreguera, Ignasi Montoriol, L. 442, 1759.1768, y Josep Noguera, L. $389,1735-1738$. 
Posteriormente el conflicto bélico de 1808 , que provocó la destrucción de las casas y la ruina de la industria textil, y el éxodo de la mano de obra artesanal hacia los nuevos enclaves fabriles del Vallès y Barcelona, sentenciaron definitivamente esta decadencia y significaron un golpe mortal para la antigua manufactura montserratina, condenada irremisiblemente a la desaparición. Así, y a pesar de que a finales del siglo xix esta zona se incorporó al proceso capitalista, ya no lo hizo con la lana como materia prima, sino con el algodón, que se había convertido en el sector rey de la industrialización catalana ${ }^{4}$.

En definitiva, pues, ni la existencia de los elementos exigidos por la protoindustria, ni la existencia de una manufactura dispersa perfectamente desarrollada eran factores suficientes para asegurar la consolidación del capitalismo.

\section{Conclusiones}

Una vez aplicados y analizados los diferentes puntos que configuran la teoría protoindustrial, ha llegado el momento de hacer el balance final. En primer lugar, hay que destacar que el paradigma se cumple en unos aspectos, pero no en otros. Las coincidencias se manifiestan en su carácter rural y disperso y en haber experimentado notables transformaciones estructurales: tanto a nivel demográfico, ya que nuestras villas experimentaron un notable incremento poblacional que hizo posible ampliar la capacidad productiva de esta industria dispersa aportando la mano de obra necesaria; como en los aspectos económicos y laborales, ya que implicó que una buena parte de la población activa pasase a depender (ya fuese de una forma total -artesanos - o parcial - campesinos-) de la actividad manufacturera y se acostumbrara a trabajar bajo las condiciones impuestas por el fabricante local o por el comerciante urbano; asumiendo una producción en masa y superando, por tanto, la etapa de autoconsumo.

Por la baja productividad y escaso desarrollo del sector agrario, con una participación del campesinado (en las operaciones de cardado e hilado) que así conseguía unos complementos salariales y se ocupaba laboralmente durante las jornadas que el campo les dejaba libres. Por la dependencia del capital comercial que controló esta manufactura a partir de la financiación y comercialización de la producción de los fabricantes agremiados y de la supeditación laboral de los sectores productivos libres. Por su penetración en las redes comerciales supracomarcales y supranacionales, participando en la dinámica

" O. Valls (1961), pp. 62 y ss. 
de intercambios a nivel regional (proporcionando tejidos a las zonas agrícolas y recibiendo a cambio alimentos) y canalizando sus paños hacia los lejanos mercados peninsulares y coloniales, consolidando así unos estrechos lazos entre los sectores productivos locales y las necesidades de estos distantes centros de consumo.

Pero en cambio coexistieron paralelamente otras características totalmente divergentes y contrarias al espíritu de la teoría. Divergencias que se materializaron en la existencia de sectores artesanales especializados en una fase técnica concreta, dedicados totalmente al trabajo manufacturero y que ya no pueden catalogarse de campesinos. En el funcionamiento de un complejo aparato gremial, al frente del cual se habían consolidado los maestros pelaires que trabajaban al margen del control del capital comercial urbano, al menos en el aspecto productivo, y que tuvieron en sus manos la dirección de una parte de la producción local. En una total autonomía humana y técnica respecto a la capital, que les permitía realizar todo el proceso sin tener que recurrir a las manufacturas urbanas. Finalmente, en que ninguna de estas dos industrias pañeras pudo consolidar su evolución capitalista, sino que se vieron afectadas por graves problemas estructurales que provocaron un retraso en el proceso de implantación fabril y que motivaron su desaparición.

En definitiva, nuestro análisis nos ha permitido corroborar una vez más el dinamismo y la diversidad manufacturera de la Cataluña preindustrial, que superó en complejidad el simple modelo concebido por F. Mendels.

Por último, cabe destacar que, a pesar de que las aportaciones de nuestra industria dispersa al nuevo modelo fabril hubiesen podido ser muy importantes, en la realidad fueron muy pobres y se limitaron a proporcionar una parte del antiguo artesano emigrado hacia los nuevos núcleos fabriles catalanes, donde formaron parte de las masas proletarias; aparte de algunos técnicos (Ortells o Reinés, entre otros) que fueron promotores de la naciente industria de indianas barcelonesa ${ }^{42}$.

La descapitalización del sector artesanal, la pervivencia de modelos productivos arcaicos, la emigración de la mano de obra y el desprestigio de la lana delante del algodón son algunas de las causas que explican el fracaso de esta antigua manufactura dispersa catalana y que nos demuestra claramente cómo no siempre la existencia de unas relaciones de producción típicamente protoindustriales tenian que permitir la consolidación y desarrollo del modelo capitalista. En esta zona la etapa preindustrial se convirtió en una fase que consumió las últimas energías de la tradicional industria dispersa.

De todas maneras hay que excluir de esta generalización algunos núclens como los siderúrgicos, que se mantuvieron activos durante buena parte del

${ }^{42}$ P. Molas (1975), pp. 188-189. 
siglo xIx, ya que eran necesarios para la consolidación de la nueva industria.

$\mathrm{O}$ laneros, como Sabadell y Terrassa, que supieron aprovechar las nuevas

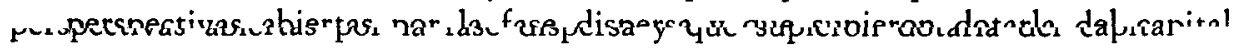
necesario para poner en marcha las innovaciones exigidas por el nuevo modelo fabril. Ellas son, pues, un claro ejemplo de cómo en determinadas circunstancias la evolución fue posible ${ }^{43}$.

Pero el modelo catalán presenta aún otra variante, ya que aquí la industria capitalista se consolidó y desarrolló de la mano de una materia nueva: el algadón, que no había conocido la fase dispersa previa y localizada en unos núcleos muy concretos, como Barcelona, que tampoco habían experimentado estadio protoindustrial ${ }^{44}$. Es decir, ésta no era una exigencia imprescindible para permitir la consolidación del nuevo modelo productivo. Como conclusión, hay que remarcar que el ejemplo catalán presenta una gran variedad de casos que reflejan, una vez más, el dinamismo y la complejidad económica de la Cataluña setecentista y, también, la existencia de diversos modelos de evolución.

${ }^{43}$ J. M. Muñoz (1984).

4 Sobre la industria algodonera catalana se pueden consultar, entre otros, los artículos de R. Grau y M. López (1974) y P. Vilar (1981). 


\section{BIBLIOGRAFIA}

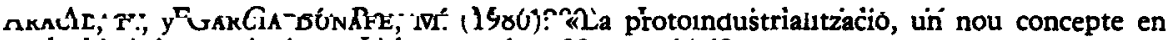
la història econòmica», L'Avenç, núm. 32, pp. 64-69.

ARACIL, R. (1983): «Indústria rural i protoindústria: aspectes generals i bibliografia», Estudis d'Història Econòmica del País Valencià, núm. 4, pp. 259-279.

Carrera Pujal, J. (1943-1946): Historia económica y política de Cataluña. Siglos XVI$X V I I I, 4$ V., Barcelona, Bosch Casa Editorial.

GonzÁlez Enciso, A. (1978): «La industria dispersa lanera en Castilla en el siglo xvin», Cuadernos de Investigación Histórica, núm. 2, pp. 269-289.

GraU, R., y LópEZ, M. (1974): «Empresari i capitalista a la manufactura catalana del segle xviII. Introducció a l'estudi de les fábriques d'indianes», Recerques, núm. 4, pp. $19-47$.

Iglésias, J. (1969): El cens del comte de Floridablanca (1787). Part de Catalunya, 2 V., Barcelona, Fundació S. Vives Casajoana.

Kriedte, P.; Medick, H., y SChlumbohm, J. (1986): Industrialización antes de la industrialización, Barcelona, Ed. Crítica.

Maluquer DE Motes, J. (1984): «La Revolució Industrial a Catalunya», L'Avenç, núm. 73. pp. 19-34.

Martínez SHaw, C. (1985): «La Cataluña del siglo xvin bajo el signo de la expansión», en R. FERnández (ed.), España en el siglo XVIII, Barcelona, Ed. Crítica, pp. 55-131.

MENDELS, F. (1972): «Proto-Industrialization: The First Phase of the Industrialization Processm, The Journal of Economic History, XXXII, pp. 241-261.

Molas Ribalta, P. (1971): «Els arrendaments públics a la Barcelona del setcents», Cuadernos de Historia Económica de Cataluña, núm. 4, pp. 89-107.

- (1975): Economia $i$ societat al segle XVIII, Barcelona, Edicions La Paraula Viva.

MUÑoz, J. M. (1984): Indústria rural $i$ industrialització: Sabadell $i$ Terrassa al segle XVIII, Barcelona (tesis de licenciatura inédita).

MUSET I PoNs, A. (1987): Indústria dispersa $i$ protoindústria a la Catalunya del segle XVIII. El cas d'Esparreguera i Olesa de Montserrat, Barcelona (tesis de licenciatura inédita).

ToRras, J. (1981): «Estructura de la indústria pre-capitalista. La draperia», Recerques, núm. 11, pp. 7-28.

- (1984): «Especialización agrícola e industria rural en Cataluña en el siglo XVIII», REvista dE Historia EconómiCa, núm. 3, pp. 113-127.

VAlLS, O. (1961): La vila d'Esparreguera $i$ el seu terme, Esparreguera.

Vilar, P. (1964-1968): Catalunya dins l'Espanya moderna, 4 V., Barcelona, Edicions 62.

- (1981): «La Cataluña industrial: reflexiones acerca de un arranque y de un destinom, en J. Fontana (ed.), La industrialización europea. Estadios y tipos, Barcelona, Ed. Crítica, pp. 173-191.

ZAMORA, F. DE (1973): Diario de los viajes bechos por Cataluña, Barcelona, Ed. Curial. 